\title{
Understanding Teachers' Resistance to the Curricular Inclusion of Alternative Algorithms
}

\author{
Randall E. Groth \\ Salisbury University
}

\begin{abstract}
This study focuses on a group of practitioners from a school district that adopted reformoriented curriculum materials but later rejected them, partially due to the inclusion of alternative algorithms in the materials. Metaphors implicit in a conversation among the group were analysed to illuminate their perspectives on instructional issues surrounding alternative algorithms. Several possible sources of resistance to folding alternative algorithms into instruction were found, including the ideas that: successful learning does not involve struggling with mathematics, the teacher's role in the classroom is primarily to present information, and that mathematics learning progresses according to a fixed sequence of levels.
\end{abstract}

There is growing consensus in the field of mathematics education that school mathematics programs should not focus solely upon conventional algorithms in teaching computation. Several studies have recommended encouraging students to invent their own algorithms rather than prematurely imposing traditional methods (Mack, 1990; Kamii \& Dominick, 1998; Carpenter, Franke, Jacobs, Fennema, \& Empson, 1998). In some cases, non-traditional algorithms can also serve to foster students' appreciation of the mathematical contributions of different cultures (Hatfield, Edward, Bitters, \& Morrow, 2003; Philipp, 1996). In light of these ideas, reform-oriented curricula have included exploration of non-standard algorithms in their instructional sequences (Carroll \& Isaacs, 2003; Romberg \& Shafer, 2003), and knowledge of alternative algorithms has become recognized as an important component of the knowledge base needed for teaching mathematics (Ball, Lubienski, \& Mewborn, 2001; Conference Board of the Mathematical Sciences, 2001).

Given the aforementioned points, teacher educators face the task of helping practitioners understand the instructional value of alternative algorithms. Simply handing teachers curriculum sequences that include the development of alternative algorithms is not sufficient, since individual teachers interpret curriculum materials differently (Collopy, 2003; Lloyd, 1999). In some cases, experiences that teachers have had with traditional mathematics curricula as students shape their interpretations of curricular materials (Lloyd \& Behm, 2005). This can lead to partial or inadequate implementation of the curricula. Therefore, an important part of reform efforts is to provide support for teachers as they attempt to implement reform-oriented recommendations for teaching mathematics (Remillard \& Bryans, 2004).

In order to support teachers in implementing reform-oriented curricula, one must understand the nature of the nature of the professional community in which they operate. The situative perspective (Greeno, 1997) holds that the discourse communities in which individuals operate strongly influence their actions. This can be problematic for teacher education. Putnam and Borko (2000) explained, "patterns of classroom teaching and learning have historically been resistant to fundamental change, in part because schools have served as powerful discourse communities that enculturate participants (students, teachers, administrators) into traditional school activities and ways of thinking" (p. 8). Since conventional algorithms hold central roles in traditional school activities, teachers 
may be resistant to the idea of moving away from them to consider alternative approaches. Understanding the specific sources of the resistance is a necessary step in designing professional development to address it.

\section{Purpose of the Study}

This report takes a case study approach to understanding possible sources of teachers' resistance to folding alternative algorithms into instruction. The study focuses upon a school district that had rejected a reform-oriented middle school curriculum (Education Development Center, 2005). After the district purchased the curriculum, few teachers used it as their guiding instructional framework. When the study took place, they were in the process of adopting a textbook to replace it, and the texts under consideration were oriented toward the instructional pattern of learning rules and practicing procedures that is prevalent in the U.S. (Stigler \& Hiebert, 1999). The district curriculum coordinator reported that some middle grades teachers had discouraged students from using alternative algorithms developed in the elementary grades, and she hypothesized that this contributed to the sharp drop-off in standardized test scores that occurred for students as they transitioned from the elementary to the middle grades. In order to understand the nature of the resistance to alternative algorithms, this study focuses upon analysing themes that were prevalent in the discourse among a group of practitioners from the district when asked to discuss the subject of alternative algorithms.

\section{Metaphor as a Lens on Discourse}

In this study, metaphorical elements of teachers' language were analysed in order to understand prevalent themes in their discourse about algorithms. Therefore, this section focuses upon introducing the concept of metaphor and explaining why it is a useful lens for examining discourse themes.

A useful definition for metaphor is that it is "a figure of speech in which a word or phrase literally denoting one kind of object or idea is used in place of another to suggest a likeness or analogy between them" (Mish, 1991, p. 746). Metaphors can help individuals understand one object or idea in terms of another. The first object or idea is often called the source and the second one the target (Gentner \& Holyoak, 1997). Any given metaphor will capture some aspects of the target while not capturing or even misrepresenting other aspects. This phenomenon is illustrated by the common saying that, "every metaphor (or analogy) limps" (note that this saying itself is a metaphor - a person with a limp is the source, while the idea of metaphor is the target). Similarities between the source and target are often called the ground of the metaphor, while dissimilarities are called the tension (Presmeg, 1998).

Petrie (1980) identified two common views about the role of metaphor in education. One view holds that "metaphors are primarily of aesthetic value, with perhaps some secondary value as heuristic aids" (p. 438). The second view is depreciative of metaphor, asserting that "metaphors are used when one is too lazy to do the hard, analytic work of determining precisely what one wants to say" (p. 438). Petrie argued that neither view is adequate, because neither acknowledges the central role that metaphor can play in learning by building a bridge from one domain to another. Lakoff and Johnson (1980) took the argument for the centrality of metaphor a step further, asserting that metaphors don't just 
provide a means for conceptualizing reality, but actually create a reality by influencing individuals' actions. Much of the essence of their theory is captured in the following quote:

\begin{abstract}
Many of our activities (arguing, solving problems, budgeting time, etc.) are metaphorical in nature. The metaphorical concepts that characterize those activities structure our present reality. New metaphors have the power to create a new reality. This can begin to happen when we start to comprehend our experience in terms of a metaphor and it becomes a deeper reality when we begin to act in terms of it. If a new metaphor enters the conceptual system that we base our actions on, it will alter that conceptual system and the perceptions and actions that the system gives rise to (Lakoff and Johnson, 1980, p. 145).
\end{abstract}

Lakoff and Johnson's theory implies that in order to understand the actions taken by individuals, one must understand the metaphors that are prevalent in the discourse communities they inhabit.

Lakoff and Johnson (1980) described several different types of metaphors that frequently turn up in discourse. Structural metaphors are those that structure one concept in terms of another. Examples of structural metaphors include "time is money," "argument is war," and "understanding is grasping." Orientational metaphors organize a system of concepts with respect to one another. Among the examples provided by Lakoff and Johnson are "happy is up, and sad is down," and "conscious is up, and unconscious is down." Ontological metaphors provide ways of viewing events, activities, ideas, and so on as substances with boundaries. Some types of ontological metaphors include talking about "moral fiber," "fame," and "fortune" as if they were well-defined substances with boundaries. Other ontological metaphors speak in terms of containers. Lakoff and Johnson give the phrase, "Are you in the race?" as an example of this type of metaphor, since the race is spoken of as an entity that may or may not contain an individual. A final type of ontological metaphor is personification. Lakoff and Johnson pointed out that a phrase such as "inflation is eating up our profits" is such a metaphor, since it ascribes the human characteristic of eating to the abstract idea of inflation. Most of the time, individuals are unaware that they are using structural, orientational, and ontological metaphors. This, however, doesn't lessen the influence the metaphors exert. On the contrary, they maintain covert influence over individuals' thinking and actions precisely because they are used and believed largely on an unconscious level.

There is a growing body of empirical support for the idea that metaphors held by teachers are related to their classroom actions. Bullough (1991) described how a group of student teachers constantly refined their personal metaphors for teaching as they went through the semester, and that those personal metaphors influenced the goals they set for themselves. Dooley (1998) provided an example of how frustration resulted when one student teacher was not able to design and implement instruction supporting his personal metaphor that characterized teaching as a give-and-take relationship between teacher and student. In a study of three mathematics teachers, Chapman (1997) found that they structured the teaching of problem-solving around metaphors of "community," "adventure," and "game." These guiding metaphors caused problem-solving to take on different characteristics in each teacher's classroom. In another study of mathematics classrooms, Presmeg (1992) described a teacher who exhibited the guiding metaphor "pure logic is beauty" during instruction, and noted that one of the students who adopted the metaphor exhibited higher levels of achievement than other students in the same class. Therefore, personal metaphors held by teachers can influence students' learning as they influence teachers' thinking, goals, and actions. 


\section{Methodology}

A qualitative design was used in the present study because the main objective was to provide insight about teachers' discourse about alternative algorithms and their role in instruction, and qualitative data are often helpful for achieving this type of objective (Bogdan \& Biklen, 1992; Miles \& Huberman, 1994). While it is expected that there will be overlap between the discourse patterns observed among the participants in the present study and those in other settings, the intent is not to make statistical claims about how prevalent the patterns of thinking observed may be in other settings. Instead, the main goal is to alert readers to some possible patterns of thinking they may encounter in working with teachers on the issue of alternative algorithms. A secondary goal is to illustrate how examining metaphorical elements of mathematics teachers' discourse can provide insights about the discourse communities in which they operate. The specific components of the qualitative design of the present study are described in detail in this section.

\section{Participants}

Nine individuals from a school district in the Mid-Atlantic U.S. participated in the study. Table 1 summarizes some more of the characteristics of the participants and assigns pseudonyms to each of them.

Table 1

Summary of Participants' Characteristics

\begin{tabular}{|c|c|c|c|}
\hline Participant & $\begin{array}{l}\text { Number } \\
\text { of years } \\
\text { teaching }\end{array}$ & $\begin{array}{l}\text { Number of } \\
\text { years teaching } \\
\text { middle school } \\
\text { mathematics }\end{array}$ & Instructional role in district \\
\hline Yvonne & 12 & 6 & $\begin{array}{l}\text { Full-time mathematics teacher at } \\
\text { middle school A }\end{array}$ \\
\hline Charles & 3 & 3 & $\begin{array}{l}\text { Full-time mathematics teacher at } \\
\text { middle school A }\end{array}$ \\
\hline Maura & 16 & 15 & $\begin{array}{l}\text { Full-time mathematics teacher at } \\
\text { middle school B }\end{array}$ \\
\hline Rhonda & 27 & 8 & $\begin{array}{l}\text { Full-time mathematics teacher at } \\
\text { middle school B }\end{array}$ \\
\hline Greg & 4 & 3 & $\begin{array}{l}\text { Full-time mathematics teacher at } \\
\text { middle school B }\end{array}$ \\
\hline Terri & 27 & 1 & School district curriculum supervisor \\
\hline Sarah & 5 & 0 (full-time) & School district resource teacher \\
\hline Kristin & 17 & 10 & School district new teacher mentor \\
\hline Barb & 23 & 0 (full-time) & $\begin{array}{l}\text { After-school and summer middle } \\
\text { school mathematics teacher }\end{array}$ \\
\hline
\end{tabular}

As mentioned earlier, the district had rejected a reform-oriented middle school curriculum, and middle school teachers were generally averse to having students study alternative algorithms. The district operated two middle schools, and participants from 
each one were included. Three taught mathematics at one district middle school, two at the other, and one taught mathematics in summer and after-school programs. Three individuals playing supporting roles for middle school mathematics instruction were also included: a new teacher mentor, a resource teacher, and the curriculum coordinator. Their inclusion resonates with Putnam and Borko's (2000) observation that the discourse communities influencing practice extend beyond just the teachers within a given group. All participants received graduate credit counting toward recertification for their participation, as it was part of a larger professional development program I had designed (Groth \& Bergner, in press).

\section{Procedure}

The professional development focusing on the issue of alternative algorithms took place on an asynchronous learning network (ALN). The defining characteristics of an ALN are: "(1) Many-to-many communication; (2) place independence; (3) time independence (that is, time-flexible, not atemporal); (4) text-based; and (5) computer-mediated interaction" (Harism, 1990, p. 43). The place and time independence features served the practical purpose of coordinating the diverse schedules of the group of practitioners. The time independence feature also served to allow extended reflection to take place. The intent was to provoke the types of prolonged and thoughtful exchanges that have taken place in other settings among mathematics teachers participating in ALNs (Newell, Wilsman, Langenfeld, \& McIntosh, 2002; Shotsberger, 1999).

As the professional development designer, I had the responsibility of setting the parameters for participation in the ALN and awarding credit for successful completion. I began the two-week ALN conversation providing the basis for this study by asking participants to read the article "Alternative Algorithms: Increasing Options, Reducing Errors" (Randolph \& Sherman, 2001). It presented and explained several alternative algorithms, including: a right-to-left partial sums algorithm for addition, an equal additions method for subtraction, a partial products algorithm for multiplication, and a scaffolding method for division. The article was intended to be an interdiscursive object (Lewis \& Ketter, 2004) to challenge the idea that traditional algorithms are somehow superior to alternative ones.

Each participant was required to make eight discussion board posts related to the ideas raised in the article (four posts the first week and four during the second). Because of previous literature showing the ill-effects of imposing extensive restrictions on the content of discussion board posts (Dysthe, 2002; Wickstrom, 2003), no more specific limitations were put on the content of participants' contributions. However, to avoid a collective monologue, it was required that three of the four posts made to the discussion board each week should be replies to other participants. The intent of this constraint was to help participants attain some of the benefits that can come from ALN participation, such as constructing knowledge collaboratively (Salmon, 2004) and engaging in productive disagreements (Matusov, 1996; Matusov, Hayes, and Pluta, 2005). I occasionally made posts to the discussion board intended to push participants toward attaining these outcomes. 


\section{Data Gathering and Analysis}

The complete transcript of the conversation among participants was captured on the software platform used to support the discussion board (Desire2Learn, 2006). At the end of the two weeks when the conversation about alternative algorithms took place, the transcript was loaded into the software program ATLAS.ti (Muhr, 2004) for retrospective analysis and coding.

The conversation transcript was coded by drawing upon the categories of metaphors described by Lakoff and Johnson (1980). Portions of text that contained structural, orientational, or ontological metaphors about algorithms, teaching, and learning were coded accordingly. For example, a transcript excerpt reading, "If we are to differentiate instruction for our students, we must know who seated in that group of students needs to start at a more advanced spot" was coded as including a structural metaphor that related learning to a journey (with some students starting at "a more advanced spot"). It was also coded as containing an ontological metaphor, since it spoke of an instructional technique (differentiated instruction) as a substance to be folded into instruction. A memo explaining the rationale for the coding was attached to each portion of text. For example, memos were attached to the aforementioned text excerpt listing the source and target analogs for each metaphor inherent in it. The content of the memos was used to form sub-categories of metaphors containing similar characteristics under each one of the Lakoff and Johnson categories (e.g., the sample text excerpt was grouped together with others that related teaching to a journey and also with those that spoke of teaching techniques as substances).

After the initial grouping of data had taken place, data analysis continued through the process of representing the study results in writing (Glesne, 1999). In particular, descriptors for subcategories within broad categories were formed as the data that had been grouped together were summarized in narrative form. The text-search feature of ATLAS.ti was used to attain a more exhaustive analysis of the transcript when new themes emerged during the writing process. For example, the text excerpt, "I commend you for sitting down with your student to help her find her mistake and still allowing her to work within her comfort zone" was initially coded as a structural metaphor conceptualizing successful learning in terms of comfort. However, it was also later categorized as a container metaphor during the process of writing, since it speaks of a "zone" in which a student is contained. Since "comfort zone" had not been initially categorized as an ontological metaphor, ATLAS.ti was used to search for other portions of the text in which the phrase occurred (in this case, there happened to be no other such instances). The prevalent metaphors that were detected in the process of data analysis are described in the next section of this paper.

\section{Results}

A summary of the total number of messages posted and how many were made by each individual each day is given in Table 2. During the two week time frame for data gathering, 107 messages were posted. Since the objective of the study was to understand ideas that were central to the practitioners' discourse about alternative algorithms, only prevalent metaphor types are described in the results section. For the purpose of the study, these were operationally defined as metaphors voiced by more than two participants. 
Table 2

Numerical Summary of Discussion Board Participation

\begin{tabular}{|c|c|c|c|c|c|c|c|c|c|c|c|c|c|c|c|}
\hline \multirow[t]{2}{*}{ Participant } & \multicolumn{15}{|c|}{ Number of messages posted each day } \\
\hline & $\begin{array}{l}\text { Day } \\
1\end{array}$ & 2 & 3 & 4 & 5 & 6 & 7 & 8 & 9 & 10 & 11 & 12 & 13 & 14 & TOTAL \\
\hline Yvonne & 0 & 0 & 0 & 1 & 3 & 0 & 0 & 0 & 0 & 2 & 0 & 2 & 0 & 0 & 8 \\
\hline Charles & 0 & 0 & 0 & 0 & 2 & 0 & 0 & 0 & 1 & 0 & 0 & 0 & 5 & 0 & 8 \\
\hline Maura & 0 & 0 & 0 & 0 & 0 & 0 & 0 & 2 & 2 & 3 & 2 & 1 & 0 & 0 & 10 \\
\hline Rhonda & 0 & 1 & 0 & 0 & 4 & 0 & 0 & 0 & 2 & 1 & 1 & 1 & 0 & 0 & 10 \\
\hline Greg & 0 & 0 & 0 & 0 & 5 & 1 & 0 & 0 & 0 & 0 & 0 & 0 & 5 & 0 & 11 \\
\hline Terri & 0 & 0 & 0 & 0 & 9 & 4 & 2 & 0 & 1 & 0 & 6 & 3 & 1 & 0 & 26 \\
\hline Sarah & 0 & 0 & 0 & 0 & 3 & 2 & 0 & 0 & 0 & 0 & 3 & 1 & 0 & 0 & 9 \\
\hline Kristin & 0 & 0 & 0 & 0 & 4 & 1 & 0 & 0 & 0 & 0 & 0 & 1 & 0 & 0 & 6 \\
\hline Barb & 0 & 0 & 0 & 0 & 5 & 0 & 0 & 0 & 0 & 0 & 6 & 0 & 0 & 0 & 11 \\
\hline Moderator & 1 & 0 & 0 & 0 & 2 & 1 & 0 & 1 & 0 & 2 & 1 & 0 & 0 & 0 & 8 \\
\hline TOTAL & 1 & 1 & 0 & 1 & 37 & 9 & 2 & 3 & 6 & 8 & 19 & 9 & 11 & 0 & 107 \\
\hline
\end{tabular}

\section{Prevalent Structural Metaphors}

Structural metaphors entered the conversation on a number of occasions. Table 3 summarizes the source and target for each of the prevalent structural metaphors, and also shows which participants voiced them during the conversation.

Several of the participants described unpleasant or difficult aspects of teaching and learning as a fight, struggle, or battle. Rhonda spoke about students' struggles to learn traditional algorithms, and saw the alternative algorithms under discussion as a way to end their struggle. At one point in the conversation, she stated, "many of our basic students struggle with the traditional multiplication, subtraction and division algorithm and for these students we must find an alternate approach." Sarah spoke of her own struggle to understand the alternative algorithms presented in the article, acknowledging that she was only familiar with traditional computational algorithms, and that she needed to read through the article several times in order to understand the algorithms discussed in it. Maura, who was not convinced of the value of anything other than the traditional algorithms, spoke of her "constant battle" to teach students "how to do math without a calculator." Barb and Terri also characterized teachers as combatants in their classrooms. Both spoke of the teacher's battle to help students make connections among concepts.

While unpleasant aspects of teaching and learning were frequently understood as a fight, struggle, or battle, successful and pleasant aspects were frequently understood in terms of physical comfort. Several participants expressed a desire for students to be comfortable in using algorithms. After reading the article, Greg and Rhonda both said that they could see value in alternative algorithms because students may be more comfortable with one of them than with the traditional algorithm. Rhonda even pointed out an algorithm for subtraction the article labelled "low stress" that might help students attain the desired degree of comfort. Terri voiced similar sentiments, saying it was important to allow a student to work "within her comfort zone" and saying, "If we fairly competent adults chose 
to use the algorithm that was most comfortable for us, why shouldn't our students have that opportunity?" At another point in the conversation, a discussion board post by Maura expressing concern that parents would not be able to help their children with homework involving alternative algorithms prompted Sarah and Greg to post statements about the need to help parents become comfortable with the algorithms along with their students. Yvonne, Charles, and Terri all recognized that in order to achieve these desired outcomes for students and parents, teachers would have to re-establish the bounds of their own "comfort" zones in mathematics. Yvonne and Charles each mentioned that teachers seem to teach the algorithms they are the most comfortable with, and Terri argued that this meant the teachers in the district would need to become comfortable with a wider range of algorithms.

Table 3

Prevalent Structural Metaphors

\begin{tabular}{|c|c|c|}
\hline Source & Target & $\begin{array}{l}\text { Participants who voiced the } \\
\text { metaphor }\end{array}$ \\
\hline A battle or struggle & $\begin{array}{l}\text { Unpleasant aspects of learning } \\
\text { mathematics }\end{array}$ & $\begin{array}{l}\text { Rhonda, Sarah, Maura, Barb, } \\
\text { Terri }\end{array}$ \\
\hline Physical comfort & $\begin{array}{l}\text { Pleasant aspects of learning } \\
\text { mathematics }\end{array}$ & $\begin{array}{l}\text { Greg, Rhonda, Terri, Maura, } \\
\text { Sarah, Yvonne, Charles, Terri }\end{array}$ \\
\hline Making a presentation & Teaching a lesson & $\begin{array}{l}\text { Charles, Barb, Rhonda, } \\
\text { Yvonne, Terri, Maura, Kristin, } \\
\text { Greg, Sarah }\end{array}$ \\
\hline $\begin{array}{l}\text { Dispenser/container } \\
\text { relationship }\end{array}$ & Teacher/student relationship & $\begin{array}{l}\text { Maura, Barb, Greg, Charles, } \\
\text { Rhonda, Yvonne }\end{array}$ \\
\hline Training & Educating teachers & $\begin{array}{l}\text { Greg, Terri, Sarah, Yvonne, } \\
\text { Rhonda, Sarah }\end{array}$ \\
\hline Learning & Taking a journey & Terri, Charles, Barb \\
\hline
\end{tabular}

Part of the reason some participants felt that teachers needed to become comfortable with a wider range of algorithms is explained by another structural metaphor prevalent among study participants: that of teaching as presenting. Charles' comment, "I think the more ways the teacher knows how to present the algorithms the more success they will have" resonated with similar remarks made by Barb and Rhonda. Barb stated that presenting a variety of algorithms to students would "make them think," while Rhonda felt that it would give them a variety of strategies from which to choose in solving problems. Yvonne, Terri, and Maura also spoke of presenting algorithms as the mathematics teacher's job. Yvonne and Maura each spoke of instances in which they felt it necessary to present traditional algorithms in class along with alternative ones, while Terri argued that they should consider the presentation of a wider range of algorithms. Kristin extended this line of conversation by suggesting that teachers should also present "the origin of the algorithm and other information that allows the student to see/be aware of/ understand the 
multicultural piece." Hence, participants felt that increased mathematics content knowledge in the area of alternative algorithms would enhance their ability to fulfil the role of teacher as presenter.

Study participants extended the "teacher as presenter" metaphor to situations beyond just teacher-student interaction in the learning of algorithms. Greg, Yvonne, Terri, and Sarah incorporated this structural metaphor in discussing teacher learning and professional development as well. They each spoke of wanting to be shown how to do the algorithms. As the curriculum coordinator, Terri responded to this request by saying that she would arrange a presenter to teach them alternative algorithms during a professional development session sponsored by the district. When the professional development session was scheduled for a time that Yvonne could not attend, she requested a "condensed presentation" of the session. Sarah and Maura each spoke of the need to show parents, and not just students, the mechanics of the alternative algorithms and why they were being used in addition to the traditional algorithms. From these instances of conversation, it was evident that the "teacher as presenter" metaphor extended to teaching and learning situations beyond the immediate bounds of the classroom.

Closely related to the "teacher as presenter" metaphor were prevalent implicit metaphors of "teacher as dispenser" and/or "student as receptacle" of information. Maura and Barb each spoke of teachers dispensing information and skills to students. Maura, for instance, argued, "We need to give these children the skills to have some number sense." Barb spoke of "giving information (about alternative algorithms) to parents and not "filling students' heads" with "too much information" when teaching. Greg, Charles, and Rhonda spoke of teachers dispensing choices to students rather than dispensing information. Each suggested that the act of showing students various alternative algorithms could help provide them with choices about how to solve a problem. This idea was also associated with the "comfort" structural metaphors, since their intention was to help students choose the method with which they were the most comfortable. Finally, Yvonne conceptualized herself as a receptacle of information in discussing her role as a teacher learning in a professional development session. She asked to "receive the information" that would be presented at the professional development session on alternative algorithms that she would not be able to attend, and lamented the fact that she had not already been "given the information" that her middle school students had apparently received in elementary school about the existence of alternative algorithms.

Professional development and teacher education themselves were frequently characterized as "training." Greg, Terri, Sarah, Yvonne, and Rhonda all made discussion board posts that contained the implicit "professional development as training" metaphor. Terri and Greg both spoke of meeting for training to implement the new textbook series that the district was considering. Yvonne and Sarah talked with one another about the differences between teacher training in language arts and mathematics. During their exchange, Sarah speculated that some of her difficulty understanding alternative algorithms came from her "inferior language arts training." Yvonne on the other hand, stated that she was not taught any alternative algorithms as she went through training to become a mathematics teacher in college. Rhonda built on Yvonne's lament, saying, "Middle school teachers should have been trained to let them know what to expect in the years ahead." Therefore, professional development was frequently understood as "training" along with "receiving information" and seeing a "presentation." 
One final type of prevalent structural metaphor was that which compared learning and understanding to a journey. This metaphor was most pronounced in Terri's posts to the discussion board, but Charles and Barb incorporated it as well. Terri argued that teachers might "thwart the progress of the students when we instruct with traditional algorithms." At another point, she said that teachers needed to construct a "backward map to the point where the students were successful and build from there." In yet another post, she talked about some students starting in a more "advanced spot" than others, and teachers should understand "where our students have been and where they are headed." Her implicit metaphors of making progress, constructing and following a map, students starting in different positions, and students heading in different directions all lent themselves to the larger structural metaphor of learning as a journey. Charles' implicit metaphors included the idea of students being in different places at different times, as he referred to the need to "know the students and where they are mathematically." Barb incorporated the metaphor of learning as a journey by stating that the acquisition of a number of alternative algorithms could "help them (students) with something down the road."

\section{Prevalent Ontological Metaphors}

Most of the prevalent ontological metaphors entering the conversation were substance metaphors. The mathematical and pedagogical ideas spoken of as substances are summarized in Table 4 along with the participants voicing the metaphors. The substance metaphors are each explained further below. In addition to the substance metaphors, a prevalent personification metaphor from the conversation is described at the end of this section, since personification metaphors fall under the category of ontological metaphors.

Table 4

Ideas Spoken of as Substances or Containers

\begin{tabular}{ll}
\hline Mathematical or pedagogical idea & Participants who voiced the metaphor \\
\hline Computational methods & All participants \\
Teaching methods & Charles, Maura, Terri, Yvonne, Barb, \\
Students' mathematical abilities & Rhonda, Greg, Kristin, Yvonne, Terri \\
Skills & Yvonne, Greg, Terri, Kristin, Maura, Barb \\
Confusion & Greg, Yvonne, Kristin, Rhonda, Terri \\
Success & Rhonda, Terri, Kristin, Sarah, Charles, Rhonda \\
Parent involvement & Charles, Barb, Maura \\
Multiculturalism & Terri, Kristin, Sarah \\
\hline
\end{tabular}

Computational methods were spoken of as substances by all participants at some point. The substances under discussion were frequently termed "traditional," "non-traditional," or "alternative" algorithms. They were also referred to more generally as "methods," "processes," or "ways" of doing computation in some cases. Though these substance metaphors were frequently used, discussions about the structures of the substances themselves rarely entered the conversation. One exception to this pattern came when Sarah commented on the structure of one of the alternative algorithms in the article, "I also like the fact that the two left to right addition partial-sum algorithms adhere to the left-to-right rule that students are taught when they learn to read." Her comment marks the most detailed analysis of the structure of an algorithm. The ALN environment in which the 
discourse took place appears to have contributed to a lack of conversation about the structure of the algorithms, as Terri made a post noting that she and Kristin worked together face to face to better understand them. Also, as noted earlier in the discussion of structural metaphors, Terri and others perceived a need for work with the algorithms in face to face professional development.

Teaching methods, like computational methods, were also frequently spoken of as substances. Charles, Maura, and Terri all spoke of a need for "differentiated instruction." Yvonne spoke of the closely related strategy of "teaching to a variety of learning styles." All four individuals spoke of these methods as substances that would help adjust instruction to suit the diverse needs of students, but did not provide detail about the nature of the methods themselves. Terri and Barb had a more detailed conversation about the "touch math" teaching strategy. When Terri asked if others in the district recalled when that particular intervention was used by special education teachers, Barb wrote back to confirm that the details she had in mind about the components of the strategy were correct. Terri responded to let Barb know that she was correct in describing it as a tactile approach to addition and subtraction. While Terri and Barb did not engage in a detailed discussion about the relative merits and drawbacks of the teaching method, their exchange does mark a higher level of analysis of teaching methods spoken of as substances than other occurrences of this type of metaphor in the discussion.

Students' mathematical abilities were spoken of in terms of a variety of substances. Rhonda, Greg, Kristin, Yvonne, and Terri all spoke of "proficiency" as a substance related to mathematical ability. Rhonda, for example, remarked that in her classes "a handful of students are proficient." Greg suggested that students who were "not proficient with the traditional (algorithms)" should use the alternative algorithms described in the article. At one point, Terri sought to locate the origin of perceived "proficiency" problems with the teachers themselves, stating, "If elementary students are proficient, and as middle school they are not, what does this say about the efficacy of our instruction?" Closely related to "proficiency" were substance metaphors of "readiness" and "competence," used by Terri and Yvonne, respectively. Other substance metaphors for students' ability entered the conversation only when individuals wished to highlight a perceived lack of ability. Greg, for instance, attributed "laziness" to some students who were unsuccessful learning traditional algorithms. This sparked an exchange with Terri, who again sought to locate the problem within teaching techniques rather than within the students. For her part, Terri framed students" lack of ability in terms of the substances of "weaknesses" and lack of "facility with algorithms" in addition to lack of "proficiency."

In another substance metaphor related to goals for students, participants frequently spoke of "skills" as valuable substances to be possessed. Yvonne, Greg, Terri, Kristin, Maura, and Barb all expressed this sentiment in the discussion board conversation. Yvonne, for example, stated, "I feel that I could be so much more help to my students if I were able to help them learn the basic skills." Kristin related the proficiency and skill substance metaphors together, expressing a desire to see students become "proficient" in skills. As with some of the other substance metaphors, no in-depth discussion took place to unpack the elements that might comprise the substances of "skills" and "basic skills." A discussion board post by the moderator requesting that participants make clear what they meant by these terms received little response. Terri acknowledged that the moderator's question was important to consider, but conversation on the matter did not proceed far beyond that point. 
Participants also spoke of "confusion" as a substance during the conversation. Greg and Yvonne each expressed concerns that students might have a large amount of confusion if instruction included both traditional and alternative algorithms. Yvonne also connected this substance metaphor with the "competence" metaphor discussed earlier, wondering, "Would our students who are somewhat competent with computation be confused if we were to attempt to teach using some of the alternative algorithms described in the article?" Yvonne's hypothesis that students would become confused seemed to arise from her own confusion reading the article under consideration, as she had acknowledged in an earlier message, "At first I was really confused when I watched my students complete problems using these algorithms." Kristin, Rhonda, and Terri each expressed their own confusion in understanding the algorithms in reply to this post by Yvonne. This exchange would infiltrate other strands of conversation, such as the "algorithms as a foreign language" structural metaphor exchange between Terri and Barb (described later). In that line of conversation and others like it, participants began to acknowledge that some of the confusion they had was generated by the fact that their own backgrounds in learning mathematics differed from those of their students.

Another substance finding its way into the conversation was that of "success." Rhonda, Terri, and Kristin each spoke of success attained by students. Rhonda noted how she had seen students attain success in computation by using some of the alternative algorithms in the article. Terri spoke of students attaining success in computation through the "touch math" teaching strategy. Kristin said that her own daughter, who went to school in the district, computed successfully using alternative algorithms. Each of these mentions of student "success" defined it in terms of attaining correct answers to computations rather than the development of mathematical reasoning and thinking processes. Sarah, Charles, and Rhonda spoke of "success" in a different situation. Each described a "parent math night" held by some teachers within the district as attaining "success." Unlike the discussion of student "success," the conversation surrounding the parent night did not contain an explicit description for what might count as success in that situation.

Parent involvement itself was spoken of as a substance among discussion board participants, and it seems likely that participants may have defined success of a parent involvement simply in terms of the amount attained. Charles and Barb both explicitly advocated holding a parent night as a way to increase the amount of parent involvement. Barb, for example, was pleased that 12 parents had come to the district's last parent night. All who mentioned parent involvement characterized it as a substance that was in short supply but needed to become more plentiful. Even Maura, who used the discussion board as a forum for expressing her dismay at the fact that she was left out of the planning of the district's last parent night, assumed that more parent involvement would be beneficial. At another point in the conversation, Charles pointed out that the new texts the district was adopting came with "take-home letters" to explain the mathematics of each unit to parents, along with a set of parent/student activities. Charles, therefore, appeared to be trying to push the conversation beyond increased quantity of parent involvement toward enhanced quality of the substance itself.

A final prevalent substance metaphor can be identified in a conversation among Terri, Kristin, and Sarah about the different cultural origins of some of the algorithms in the article under discussion. In this strand of the discussion board, "multiculturalism" could be identified as the substance under consideration. Terri noted that the state governing agency for education wanted to see more examples of "multiculturalism" in instruction, and called 
the algorithms in the article "good examples." Kristin affirmed Terri's comment in a later post. Sarah joined this strand of conversation to emphasize that teaching the history behind each algorithm would also be important in establishing a "multicultural connection," thus pushing the discussion a bit further in the direction of how best to infuse "multiculturalism" into the curriculum by drawing upon the algorithms.

The final prevalent ontological metaphor was a personification metaphor concerning algorithms. Algorithms frequently ascribed the characteristics of being "unfamiliar" and needing "introduction." Rhonda and Barb both spoke of a need to "familiarize" themselves with alternative algorithms that their middle school students used. Traditional algorithms were described as needing to be "introduced" to students by Rhonda and Terri. Rhonda, for example, stated, "At some place in time, many of our students were introduced to traditional algorithms" when discussing the roles of alternative and traditional algorithms in instruction. Maura expressed her view on the role of alternative algorithms in instruction in stating, "If a child cannot learn the traditional way, then introduce them to something else," conceptualizing non-traditional algorithms as somewhat of a safety net rather than a starting point. Sarah and Terri each noted that parents' unfamiliarity with the algorithms was problematic, tying in with conversational themes about parent involvement discussed earlier. Maura voiced perhaps the most vivid personification metaphor to convey parents' unfamiliarity with the algorithms. She stated at one point, "For most parents, the (alternative) algorithms are foreign," implicitly characterizing the algorithms to be citizens of a nation other than that of the students' parents.

\section{Prevalent Orientational Metaphor}

There was one prevalent orientational metaphor in the conversation: study participants frequently referred to some types of mathematics as being "higher" than others. Greg used this kind of language in speaking about how some parents are uncomfortable with "higher math" such as pre-algebra or algebra. Terri spoke of "higher level math" when citing internet research she had done on the lattice algorithm for multiplication. She stated, "I really like the lattice algorithm. In searching that algorithm, I found that it is used for higher level math and many kinds of problem solving - from glacier melt to weather - to public planning." Greg and Yvonne spoke of various levels of mathematics as well. Greg stated, "I teach eighth grade, but my students are still trying to learn on the 4th grade level or so," and went on to say that every student should have an algorithm that "they are comfortable enough with to use with proficiency at this level." Yvonne felt that she should have been told when students at the "elementary level" began to use alternative algorithms for computation, so that she wouldn't have been surprised when they arrived in middle school. In order to address this problem, Terri stated that she was trying to convince the district to hire a mathematics coordinator who would work with all "levels" from elementary to high school. It was apparent that some work toward coordination of the "lower" and "higher levels" of mathematics teachers in the district had already begun, as both Yvonne and Rhonda mentioned attending "vertical team meetings" of teachers from various "levels" of teaching.

\section{Discussion}

The purpose of this paper was to provide guidance for teacher educators by describing some discourse patterns they might encounter in working with teachers and by providing a 
description of a diagnostic method used to understand the underlying themes. My intent in this section is to provide a synthesizing analysis of the prevalent metaphors in the discourse among the study participants, recognizing that readers are likely to draw their own naturalistic generalizations (Stake \& Trumbull, 1982) through their own analyses of the results described earlier. In this synthesizing analysis, prevalent metaphors are grouped into four clusters.

\section{Cluster 1: Tension between Comfort and Struggle}

Figure 1 depicts participants' tendencies to think of positive aspects of teaching and learning in terms of "comfort" and unpleasant aspects in terms of a fight or a struggle. Prevalent metaphors that entered the conversation appear within rectangles, and supporting details for each appear in the ovals connected to them. Figure 1 portrays the tension between the struggle and comfort metaphors, and also indicates that since "confusion" was spoken of as a substance to be reduced, it fed into the prevalent structural metaphor depicting negative aspects of teaching and learning as a struggle.

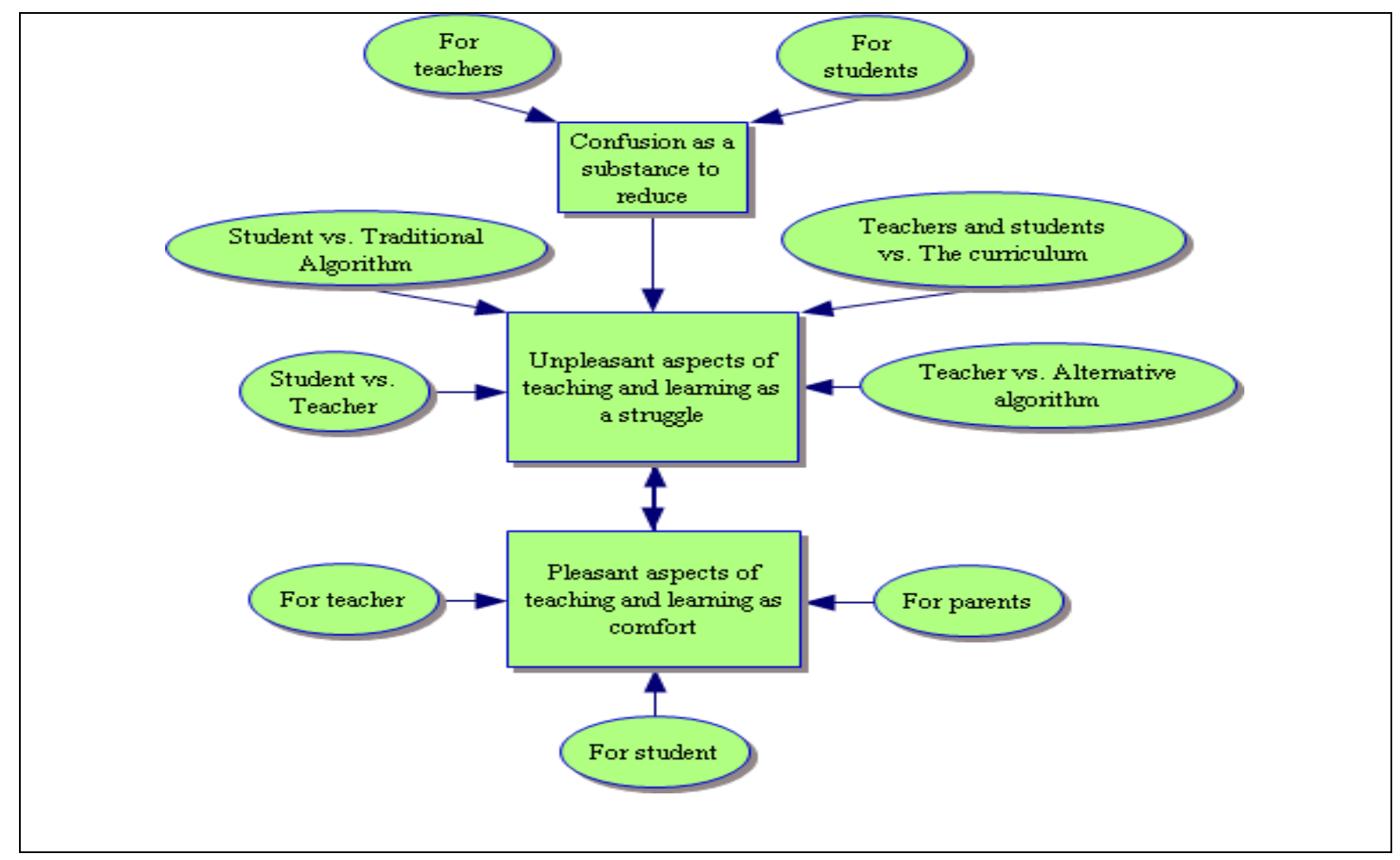

Figure 1. Comfort and struggle metaphors for teaching and learning.

The tendency to think in terms of the "comfort" and "struggle" metaphors counteracts the implementation of current reform-based mathematics curricula, and therefore partially explains why teachers in this particular setting had actively rejected this type of curriculum. Reform-based curricula emphasize the need for a degree of uncertainty to exist as students are working on mathematics (Zaslavsky, 2005). Appropriate levels of uncertainty can spark the cognitive conflict necessary for learning to take place (Piaget, 1983). When students do make mistakes in problem-solving, they should be seen as potential learning sites rather than simply nuisances or obstacles to be overcome (Hiebert, Carpenter, Fennema, Fuson, \& Wearne, 1997). Making the shift toward this sort of teaching is a non-trivial matter 
(Heaton, 2000; Lampert, 2001). Some teachers, not wanting to see students struggle to any extent, lower the levels of cognitive demand inherent in reform-based mathematical tasks by demonstrating rules or procedures that can be used to solve challenging problems (Stein, Grover, \& Henningsen, 1996). Therefore, an important learning goal for teachers holding similar metaphors related to "comfort" and "struggle" is to develop an understanding of how cognitive conflict can play a role in learning.

\section{Cluster 2: Transmission-based Conceptions of Teaching and Learning}

Figure 2 depicts interrelationships among prevalent metaphors that suggest that information is to be directly transmitted from teacher to student. In the conversation, the teacher was frequently portrayed as an introducer or dispenser of information to students. Study participants also applied these types of metaphors to their own learning, frequently expressing the desire to be "shown" the algorithms in "training" sessions.

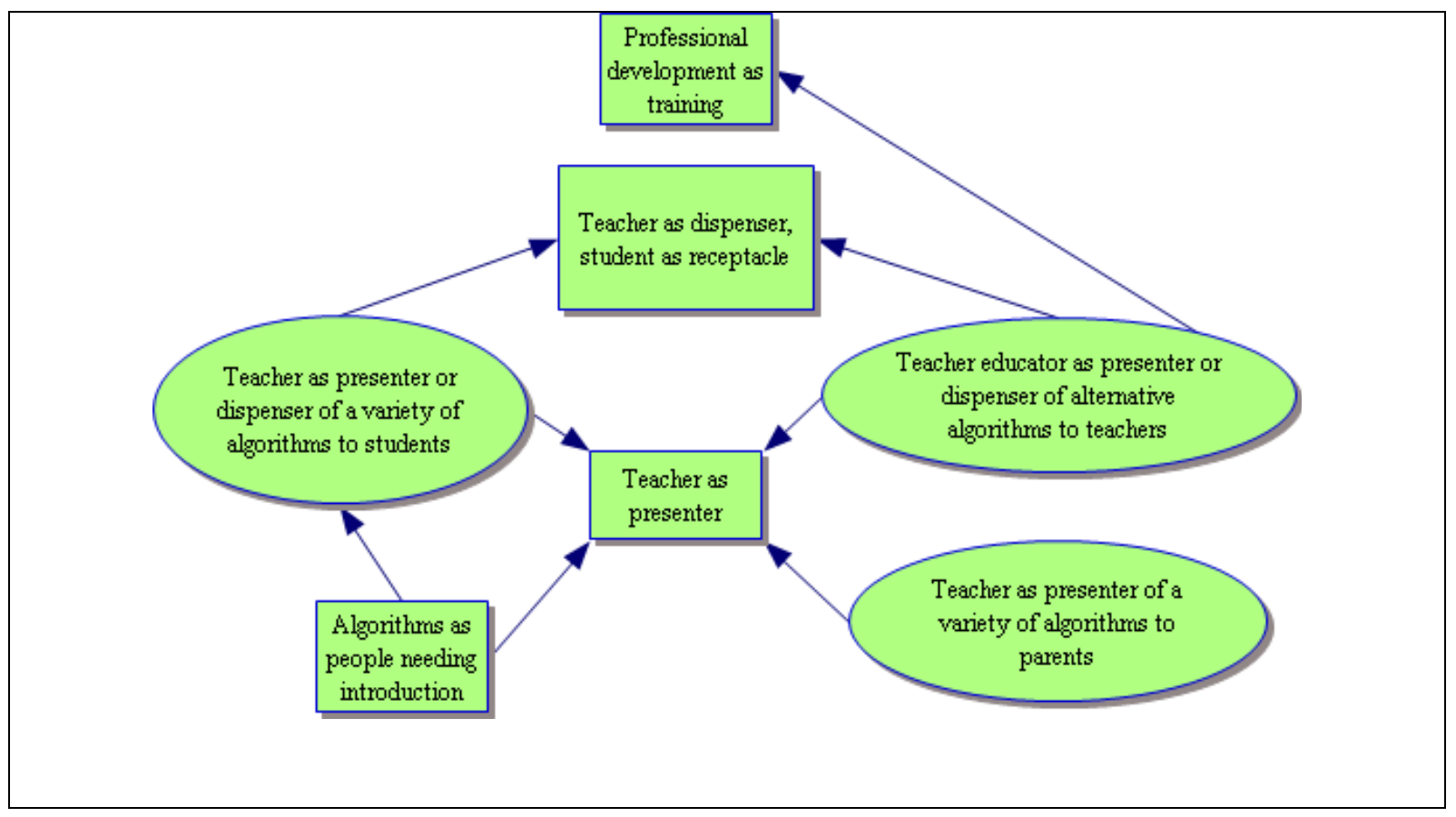

Figure 2. Metaphors suggesting transmission-based conceptions of teaching and learning

Transmission-based conceptions of teaching and learning also clearly work against the implementation of reform-oriented curricula. Such conceptions leave no room for encouraging students to invent their own algorithms, a process that is important to students' mathematical development (Mack, 1990; Carpenter, Franke, Jacobs, Fennema, \& Empson, 1998). While some participants in the conversation did hint that they would consider changing their practices in the direction of "introducing" more alternative algorithms, none mentioned encouraging students to invent their own. A moderator post questioning the practice of "introducing" algorithms drew little response, perhaps because of the nature of the asynchronous environment - participants were free to respond or not respond to any given post. Continued professional development about this idea was clearly needed, particularly in light of research demonstrating the harm teachers can produce by imposing algorithms on students too early on in their mathematical development (Erlwanger, 1973; Kamii \& Dominick, 1998). 


\section{Cluster 3: Ill-Defined Substances in the Discourse}

Figure 3 depicts how some of the topics of conversation among study participants took the form of ill-defined substances. Prevalent metaphors are again shown in rectangles, with supporting details in ovals.

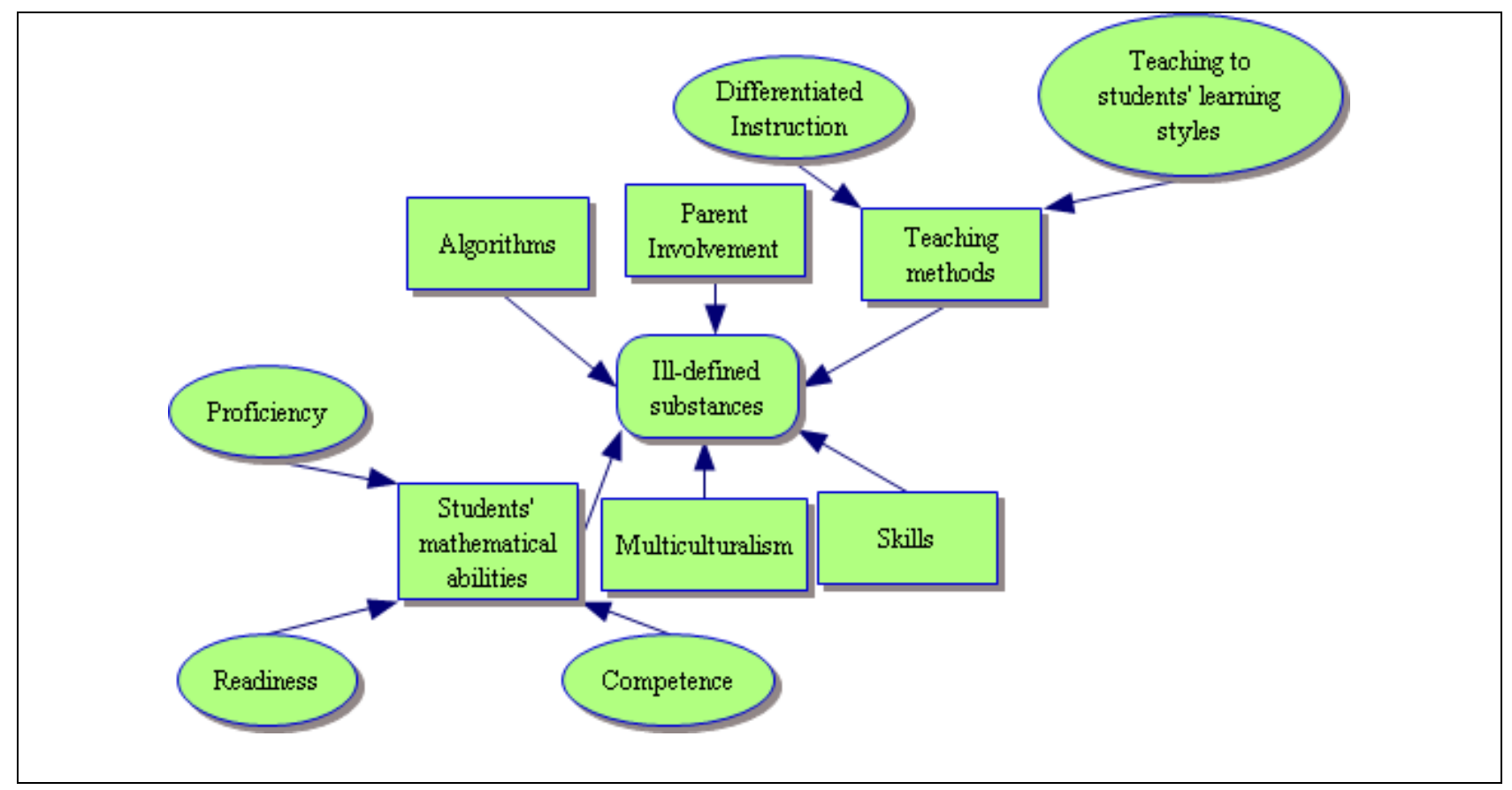

Figure 3. Ill-defined substances that entered the discourse

For each of the prevalent metaphors included in the cluster, there was a degree of doubt about the extent to which participants agreed on the nature of the concept under discussion. For example, Terri's comments on students' mathematical "proficiency" were framed in terms of the benchmarks on high stakes tests, but it was not clear that others were speaking of proficiency in the same manner. Attempts by the moderator to get participants to explain what they meant by "skills" in mathematics were largely unsuccessful. Ideas like "differentiated instruction" and "teaching to students' learning styles" were introduced as teaching methods with the implicit assumption that everyone had a common understanding of them. The substances metaphors of "parent involvement" and "multiculturalism" were not examined carefully. Instead, it was assumed that the more parent involvement, the better, and that introducing algorithms such as "Russian Peasant Multiplication" would somehow tie in with goals for infusing multiculturalism into the curriculum. In these cases, shifts in the discourse among participants were needed to unpack substance metaphors, such as re-framing the discussion of parent involvement in qualitative rather than quantitative terms (Ogawa, 1998), considering the multi-faceted nature of multicultural education (Nieto, 1992), and problematising ideas such as "teaching to different learning styles" (Klein, 1997). While most of these ideas are only indirectly related to the teaching and learning of algorithms, the larger discourse pattern they illustrate is that of fairly uncritical acceptance or rejection of curricular ideas. 


\section{Cluster 4: Upward Vertical Journey Metaphors}

Figure 4 illustrates that two different prevalent metaphors suggested that participants viewed teaching as an upward vertical journey. The structural metaphor of "teaching as a journey" entered the conversation along with a number of suggestions that elementary school mathematics was at a lower level, vertically, than middle and high school mathematics.

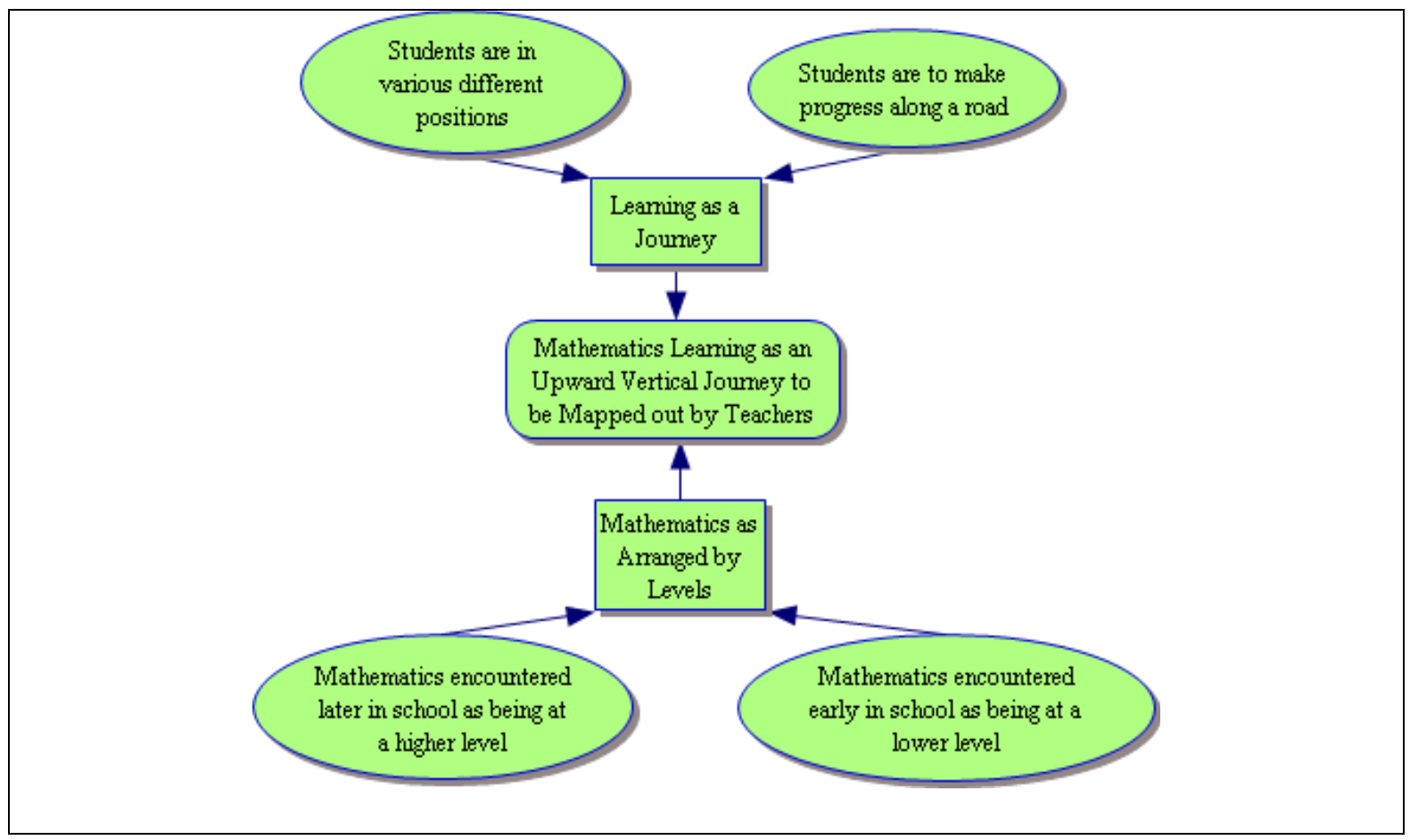

Figure 4. Upward vertical journey cluster.

Metaphors suggesting that learning as an upward vertical journey have worked their ways well into the fabric of the profession of education. Because of this, it is valuable to ask educators to step back from time to time to examine the tension inherent in such metaphors. Ma's (1999) work is instructive for this purpose, because it demonstrates how "low level" topics like fraction division and whole number subtraction can be hard to understand conceptually even for teachers who have "reached high levels" of attainment within the school system. Many of the teachers she interviewed were enrolled in Master's degree programs, yet could not write word problems to model fraction division or explain why one sometimes must regroup when subtracting whole numbers. While most all of them could perform the procedures of fraction division and whole number subtraction, few exhibited the type of mathematical knowledge that is essential to teaching (Hill, Rowan, \& Ball, 2005). For such teachers, learning is perhaps better conceptualized as beginning with a "downward vertical journey" followed by an extended exploration of what they find when they reach the level where fundamental ideas from elementary mathematics reside. Some participants in the present study appear to have recognized the need to take such downward vertical journey so they could better understand the alternative algorithms their students brought from elementary school to middle school. Nonetheless, the idea of mathematical learning as an upward vertical journey remained prevalent. 


\section{Conclusion}

Near the end of her review of pedagogical approaches in research on teacher education, Grossman (2005) remarked,

As a field, research on teacher education has expended relatively little effort in building the tools of the trade. Yet, as work in the biological sciences and genetics suggests, having the right tools for investigating complex phenomena can make all the difference in what we are able to see (p. 451).

The present study demonstrates how metaphorical analysis can serve as a tool for understanding the complex phenomenon of mathematics teachers' discourse. The analysis undertaken in this study resulted in the identification of several important functions that professional development needed to serve for a particular group of teachers. While the specific needs of the group of practitioners studied may or may not overlap with those of other groups, the tool of metaphorical analysis itself is not bound to context (Lakoff \& Johnson, 1980). Therefore, in addition to identifying some of the patterns of thinking that may impede teachers' understanding and acceptance of alternative algorithms, the present study illustrates the use of a tool for understanding teachers' thinking that transcends contextual boundaries of subject matter and geographic location. With knowledge of teachers' thinking in hand from this type of metaphorical analysis, teacher educators can make informed decisions about appropriate forms of instruction for the teachers they serve.

\section{References}

Ball, D.L., Lubienski, S.T., \& Mewborn, D.S. (2001). Research on teaching mathematics: The unsolved problem of teachers' mathematical knowledge. In V. Richardson (Ed.), Handbook of research on teaching (4th edition) (pp. 433-456). New York: Macmillan.

Bogdan, R.C., \& Biklen, S.K. (1992). Qualitative research for education: An introduction to theory and methods. Boston: Allyn and Bacon.

Bullough, R.V. (1991). Exploring personal teaching metaphors in preservice teacher education. Journal of Teacher Education, 42, 43-51.

Chapman, O. (1997). Metaphors in the teaching of mathematical problem solving. Educational Studies in Mathematics, 32, 201-228.

Collopy, R. (2003). Curriculum materials as a professional development tool: How a mathematics textbook affected two teachers' learning. Elementary School Journal, 103, 287-311.

Carpenter, T.P., Franke, M.L., Jacobs, V.R., Fennema, E., \& Empson, S.B. (1998). A longitudinal study of invention and understanding in children's multidigit addition and subtraction. Journal for Research in Mathematics Education, 29, 3-20.

Carrol, W.M., \& Isaacs, A. (2003). Achievement of students using the University of Chicago School Mathematics Project's Everyday Mathematics. In S.L. Senk \& D.R. Thompson (Eds.), Standards-based school mathematics curricula: What are they? What do students learn? (pp. 79-108). Mahwah, NJ: Lawrence Erlbaum Associates.

Conference Board of the Mathematical Sciences. (2001). The mathematical education of teachers. Providence, Rhode Island: American Mathematical Society.

Desire2Learn (2006). Desire2Learn: Innovative teaching technology. Retrieved February 2, 2006 from http://www.desire2learn.com/index.asp.

Dooley, C. (1998). Teaching as a two-way street: Discontinuities among metaphors, images, and classroom realities. Journal of Teacher Education, 49, 97-107.

Dysthe, O. (2002). The learning potential of a web-mediated discussion in a university course. Studies in Higher Education, 27, 339-352.

Education Development Center. (2005). MathScape: Seeing and thinking mathematically. Retrieved February 2, 2006 from http://www2.edc.org/Mathscape/phil/default.asp.

Erlwanger, S.H. (1973). Benny's conception of rules and procedures in IPI mathematics. Journal of Children's Mathematical Behaviour, 1 (Autumn 1973), 7-26.

Gentner, D., \& Holyoak, K.J. (1997). Reasoning and learning by analogy. American Psychologist, 52, 32-34. 
Glesne, C. (1999). Becoming qualitative researchers: An introduction (2nd ed.). New York: Longman.

Greeno, J.G. (1997). On claims that answer the wrong questions. Educational Researcher, 26 (1), 5-17.

Grossman, P. (2005). Research on pedagogical approaches in teacher education. In M. Cochran-Smith \& K.M. Zeichner (Eds.), Studying teacher education: The report of the AERA panel on research and teacher education (pp. 425-476). Mahwah, NJ: Erlbaum.

Groth, R.E., \& Bergner, J.A. (in press). Building an online discussion group for teachers. Mathematics Teaching in the Middle School

Harism, L.M. (1990). Online education: An environment for collaboration and intellectual amplification. In L.M. Harism (Ed.), Online education: Perspectives on a new environment (pp. 39-64). New York: Praeger.

Hatfield, M.M., Edwards, N.T., Bitter, G.G., \& Morrow, J. (2003). Mathematics methods for elementary and middle school teachers (4th ed.). New York: John Wiley \& Sons.

Heaton, R.M. (2000). Teaching mathematics to the new standards: Relearning the dance. New York: Teachers College Press.

Heibert, J., Carpenter, T.P., Fennema, E., Fuson, K.C., \& Wearne, D. (1997). Making sense: Teaching and learning mathematics with understanding. Portsmouth, NH: Heinemann.

Hill, H.C., Rowan, B., \& Ball, D.L. (2005). Effects of teachers' mathematical knowledge for teaching on student achievement. American Educational Research Journal, 42, 371-406.

Kamii, C.K., \& Dominick, A. (1998). The harmful effects of algorithms in grades 1-4. In L.J. Morrow (Ed.), The teaching and learning of algorithms in school mathematics (pp. 130-140). Reston, VA: National Council of Teachers of Mathematics.

Klein, P.D. (1997). Multiplying the problems of intelligence by eight: A critique of Gardner's theory. Canadian Journal of Education, 22, 377-394.

Lakoff, G., \& Johnson, M. (1980). Metaphors we live by. Chicago: University of Chicago Press.

Lampert, M. (2001). Teaching problems and the problems of teaching. New Haven: Yale University Press.

Lewis, C., \& Ketter, J. (2004). Learning as social interaction: Interdiscursivity in a teacher and researcher study group. In R. Rogers (Ed.), Introduction to critical discourse analysis in education (pp. 117-146).

Lloyd, G.M. (1999). Two teachers' conceptions of a reform-oriented curriculum: Implications for mathematics teacher development. Journal of Mathematics Teacher Education, 2, 227-252.

Lloyd, G.M., \& Behm, S.L. (2005). Preservice elementary teachers' analysis of mathematics instructional materials. Action in Teacher Education, 26, (4), 48-62.

Ma, L. (1999). Knowing and teaching elementary mathematics. Mahwah, NJ: Lawrence Erlbaum Associates.

Mack, N.K. (1990). Learning fractions with understanding: Building on informal knowledge. Journal for Research in Mathematics Education, 21, 16-32.

Matusov, E. (1996). Intersubjectivity without agreement. Mind, Culture, and Activity, 3, 25-45.

Matusov, E., Hayes, R., \& Pluta, M.J. (2005). Using discussion webs to develop an academic community of learners. Educational Technology \& Society, 8 (2), 16-39.

Miles, M.B., \& Huberman, A.M. (1994). Qualitative data analysis. Thousand Oaks, CA: Sage.

Mish, F.C. (Ed.). (1991). Webster's ninth new collegiate dictionary. Springfield, MA: Merriam-Webster.

Muhr, T. (2004). User's Manual for ATLAS.ti 5.0. Berlin: ATLAS.ti Scientific Software Development.

Newell, G., Wilsman, M., Langenfeld, M., \& McIntosh, A. (2002). Online professional development: Sustained learning with friends. Teaching Children Mathematics, 8, 505-508.

Nieto, S. (1992). Affirming diversity: The sociopolitical context of multicultural education. White Plains, NY: Longman.

Ogawa, R.T. (1998). Organizing parent-teacher relations around the work of teaching. Peabody Journal of Education, 73, 6-14.

Petrie, H. (1980). Metaphor and learning. In A. Ortony (Ed.), Metaphor and thought (pp. 438-461). Cambridge: Cambridge University Press.

Philipp, R.A. (1996). Multicultural mathematics and alternative algorithms. Teaching Children Mathematics, 3, 128-133.

Piaget, J. (1983). Piaget's theory. In P. Mussen (Ed.) Handbook of child psychology (pp. 103-128). New York: John Wiley \& Sons.

Presmeg, N.C. (1992). Prototypes, metaphors, metonymies and imaginative rationality in high school mathematics. Educational Studies in Mathematics, 23, 595-610.

Presmeg, N.C. (1998). Metaphoric and metonymic signification in mathematics. Journal of Mathematical Behaviour, 17, 25-32. 
Putnam, R.T., \& Borko, H. (2000). What do new views of knowledge and thinking have to say about research on teacher learning? Educational Researcher, 29 (1), 4-15.

Randolph, T.D., \& Sherman, H.J. (2001). Alternative algorithms: Increasing options, reducing errors. Teaching Children Mathematics, 8, 480-484.

Remillard, J.T., \& Bryans, M.B. (2004). Teachers' orientations toward mathematics curriculum materials: Implications for teacher learning. Journal for Research in Mathematics Education, 35, 352-388.

Romberg, T.A., \& Shafer, M.C. (2003). Mathematics in Context - Preliminary evidence about student outcomes. In S.L. Senk \& D.R. Thompson (Eds.), Standards-based school mathematics curricula: What are they? What do students learn? (pp. 225-250). Mahwah, NJ: Erlbaum.

Salmon, G. (2004). E-Moderating: The Key to Teaching and Learning Online. London: RoutledgeFalmer.

Shotsberger, P.G. (1999). The INSTRUCT Project: Web professional development for mathematics teachers. Journal of Computers in Mathematics and Science Teaching, 18, 49-60.

Stake, R.E., \& Trumbull, D.J. (1982). Naturalistic generalizations. Review Journal of Philosophy and Social Science, 7, 1-12.

Stein, M. K., Grover, B. W., \& Henningsen, M. (1996). Building student capacity for mathematical thinking and reasoning: An analysis of mathematical tasks used in reform classrooms. American Educational Research Journal, 33(2), 455-488.

Stigler, J.W. \& Hiebert, J. (1999). The teaching gap. New York: The Free Press.

Wickstom, C.D. (2003). A funny thing happened on the way to the forum. Journal of Adult and Adolescent Literacy, 46, 414-423.

Zaslavsky, O. (2005). Seizing the opportunity to create uncertainty in learning mathematics. Educational Studies in Mathematics, 60, 297-321.

\section{Author}

Randall E. Groth, Education Department, Salisbury University, Salisbury, MD 21801, USA. Email: <regroth@ salisbury.edu> 